\title{
Determinants of nurse absenteeism and intent to leave: An international study
}

\author{
Elizabeth A. Burmeister ${ }^{1}$ | Beatrice J. Kalisch ${ }^{2}$ | Boqin Xie ${ }^{3}$ | Myrna A. A. \\ Doumit $^{4}$ | Eunjoo Lee ${ }^{5}$ | Annamaria Ferraresion, ${ }^{6,7}$ | Fusun Terzioglu ${ }^{8}$ | Helga Bragadóttir ${ }^{9}$
}

${ }^{1}$ Princess Alexandra Hospital, Wolloongabba and University of Queensland, Brisbane, Australia

${ }^{2}$ University of Michigan School of Nursing, Ann Arbor, Michigan

${ }^{3}$ Fudan University, School of Nursing, Shanghai, China

${ }^{4}$ Lebanese American University, Beirut, Lebanon

${ }^{5}$ Kyngpook National University, Daegu, South Korea

${ }^{6}$ Policlinico di Modena, Modena, Italy

${ }^{7}$ Italian Missed Care Study Group, Italy

${ }^{8}$ Faculty of Health Sciences, Atilim University, Ankara, Turkey

${ }^{9}$ University of Iceland, Faculty of Nursing and Landspitali University Hospital,

Reykjavik, Iceland

\section{Correspondence}

Elizabeth A. Burmeister, Princess Alexandra Hospital, Woolloongabba, QLD 4102, Australia.

Email: liz.burmeister@health.qld.gov.au

\begin{abstract}
Aim: To determine factors associated with nurses' intent to leave their positions and absenteeism.

Background: There is a recognized global shortage of nurses but limited data describing and determining factors associated with nurse absenteeism and intent to leave. Methods: This study involved a secondary analysis of the results from direct-care registered nurses' responses to the MISSCARE Survey, with data from seven countries included. Multi-level modelling was used to determine nurse characteristics and working environment factors associated with nurse absenteeism and intent to leave. Results: The level of absenteeism and intent to leave varied significantly across countries, with registered nurses in Lebanon reporting the highest intention to leave within 12 months (43\%) and registered nurses in Iceland and Australia the highest level of absenteeism (74\% and 73\%, respectively). Factors associated with outcomes included perceived staffing adequacy of unit, job satisfaction, and age of the nurse. Conclusions: A significant difference between countries was identified in nurse absenteeism and intent to leave. Increased perception of unit staffing inadequacy, lower job satisfaction, less nurse experience, and younger age were significant contributors to nurse absenteeism and intent to leave.

Implications for Nursing Management: These findings suggest that regardless of country and hospital, by ensuring that units are adequately staffed and increasing job satisfaction, younger, less experienced nurses can be retained and absenteeism reduced.
\end{abstract}

\section{KEYWORDS}

absenteeism, intent-to-leave, job satisfaction, nursing, staffing

\section{1 | INTRODUCTION}

A shortage of nurses is a serious problem, negatively affecting healthcare around the globe (Institute of Medicine, 2010; International Council of Nurses, 2013; Oulton, 2006; Walker, 2010). According to the Institute of Medicine (IOM) Future of Nursing report (Institute of Medicine, 2010), it is essential for the overall safety and quality of care that enough skilled nurses are employed. Compounding this problem is the phenomenon known as nurse migration, where nurses leave their country of origin to work elsewhere. In 2007, the
International Council of Nurses released a position statement on nurse retention and migration calling on the member associations in each country, governments, employers, and nurses to focus their attention and actions urgently on retention issues (International Council of Nurses, 2007).

The reasons for the nurse shortage are multifaceted but working conditions are a major contributor (Aiken et al., 2011; Rosenkoetter \& Nardi, 2007), and a substantial number of nurses intend to leave the nursing profession (Estryn-Behar et al., 2007). An Academy of Nursing White Paper points to a "high-stress work environment with 
increasing volume and acuity, unsafe workplace conditions, mandatory overtime, burnout, and job dissatisfaction" (Rosenkoetter \& Nardi, 2007, p. 306) as factors leading to nurse shortages. Former studies on nurses' intention to leave and their absenteeism from work indicated a relationship between these variables and job satisfaction (Hairr, Salisbury, Johannsson, \& Redfern-Vance, 2014; Roelen et al., 2013; Sabanciogullari \& Dogan, 2015; Yurumezoglu \& Kocaman, 2015). Study findings have further shown a relationship of intent to leave to personal factors such as marital status (El-Jardali et al., 2013) and work-family conflicts (Estryn-Behar et al., 2007) as well as work-related factors such as burnout, quality of teamwork, and satisfaction with pay (Estryn-Behar et al., 2007), autonomy, peer support, physical, and psychological demands and long working hours (Han, Trinkoff, \& Gurses, 2015; Heinen et al., 2013).

In this study, we compare nurses' intention to leave, absenteeism, job satisfaction, overtime, perception of adequate staffing levels, and patient turnover (number of admissions and discharges) in seven countries in various parts of the world. We also investigated if nurse characteristics, including age and experience, and work factors, including perceived adequate staffing, overtime, and job satisfaction across countries, were associated with nurses' intent to leave and absenteeism.

\section{RESEARCH QUESTIONS}

The objectives of this study were (a) to describe how nurse characteristics, including age, education, experience and job satisfaction, intent to leave, absenteeism, overtime, perceived staffing adequacy, and patient turnover vary by country, and (b) whether nurse characteristics and nurses' perception of adequate staffing, patient turnover during shifts, job satisfaction and overtime is associated with nurses' intent to leave and absenteeism across countries.

\section{3 | METHOD}

\section{1 | Design, sample, and setting}

A cross-sectional design was used for this study. The study sample consisted of registered nurses (RNs) who provided direct inpatient care in seven countries: Australia, Iceland, Italy, South Korea, Lebanon, Turkey and the United States. All participants worked in medical-surgical, rehabilitative, intermediate, and intensive care patient units in acute care hospitals.

The Australian sample consisted of 364 RNs, (return of questionnaire percentage: $31 \%$ ) from one hospital (830 beds). In Iceland, the participants ( $n=344$, return percentage $69 \%$ ) worked in eight hospitals (ranging in size from eight to 670 beds). For Italy, the study sample of 878 RNs (return percentage $81 \%$ ) worked in five hospitals (ranging in size from 450 to 1,407 beds). For South Korea, 555 RNs (return percentage $87 \%$ ), working in two academic medical centres and one teaching hospital, participated. The Lebanon sample comprised of 118 RNs (return percentage 44\%) who worked in one large teaching hospital ( 250 beds). Registered nurses $(n=406)$ working in two university hospitals (913 and 1,053 beds) made up the sample in Turkey, with a return percentage of $80 \%$. The US sample $(n=3,538$, return percentage of 59\%) came from 11 hospitals (ranging in size from 60 to 913 beds).

Although there may be some slight difference in role descriptions of the participating nurses from one country to another, it is assumed that participants' core responsibilities align with the definition of the International Council of Nurses (ICN), which states that a nurse is.

... a person who has completed a program of basic, generalized nursing education and is authorized by the appropriate regulatory authority to practice nursing in his/her country ... The nurse is prepared and authorized (1) to engage in the general scope of nursing practice, including the promotion of health, prevention of illness, and care of physically ill, mentally ill, and disabled people of all ages and in all health care and other community settings; (2) to carry out health care teaching; (3) to participate fully as a member of the health care team; (4) to supervise and train nursing and health care auxiliaries; and (5) to be involved in research.

(International Council of Nurses, 2018)

Nurses' associations in all the participating countries are members of the ICN, so this definition applied to all our participants (International Council of Nurses, 2014).

\subsection{Measures}

Data for all measures for this analysis were gathered using responses from the MISSCARE Survey. The MISSCARE Survey contains questions about how satisfied the respondents are with their current position, their occupation as a whole, and the level of teamwork on their units. Responses were made on a Likert scale ranging from 1 (very dissatisfied) to 5 (very satisfied). The test-retest reliability for satisfaction with current position was 0.89 , for occupation satisfaction was 0.66 , and 0.92 for satisfaction with teamwork (Kalisch, Lee, \& Rochman, 2010). Satisfaction responses were dichotomized into satisfied or not, with responses on the Likert scale of 1 to 3 classified as not satisfied and a response of 4 and 5 classified as satisfied. Survey respondents were also asked whether they planned to leave their current position in the next 6 months, or in the next year, or whether they had no plans to leave within the year. Work hours per week were measured as a dichotomous variable where participants were asked whether they worked $\geq 30 \mathrm{hr}$ or $<30 \mathrm{hr}$. Number of working hours for full time equivalence (FTE) varies between countries and in this study $\geq 30$ working hours per week is defined as FTE. To measure absenteeism, the survey respondents were asked "in the past 3 months, how many days or shifts did you miss work due to illness, injury, extra rest etc (exclusive of approved days off)?" Overtime was 
measured by asking survey respondents: "In the past 3 months, how many hours of overtime did you work?" This was categorized into three categories: none, 1 to $12 \mathrm{hr}$, and more than $12 \mathrm{hr}$. The responses of intention to leave and absenteeism were dichotomized as intent to leave within the next 12 months yes or no, and absent or not within the last 3 months. Level of staffing was measured using two variables: first, the perception by nurses of staffing adequacy from adequate $100 \%, 75 \%, 50 \%, 25 \%$ or $0 \%$ of the time. Secondly patient turnover was measured by summing the number of admissions and discharges during the nurse's previous shift (Kalisch, 2015). The question on satisfaction with current role was omitted in Australia due to the risk of breaching confidence as data were collected only in one hospital. The question on satisfaction with teamwork was omitted in Turkey based on methodological weaknesses of the translated question into Turkish.

The English version of the MISSCARE Survey was used in the United States, Australia, and Lebanon. For the other countriesIceland, Italy, South Korea, and Turkey-the survey was translated from English into Icelandic, Italian, Korean, and Turkish using a stepby-step translation process, including preparation, translation, back translation, adjudication, pretest, revision, and test-retest (Bragadóttir, Kalisch, Smáradóttir, \& Jónsdóttir, 2015). The process used was designed to ensure the meaning was not lost or changed during the translation. Cronbach's $\alpha$ coefficients for the MISSCARE survey in the counties of Australia, Iceland, Italy, Lebanon, Turkey, South Korea and USA were $0.91,0.89,0.94,0.91,0.91,0.93$, and 0.92 respectively.

\section{3 | Procedures}

After acquiring the approval of institutional review boards at each of the participating hospitals in each country, survey packets containing (a) a letter ensuring participant confidentiality and explaining the study; (b) the MISSCARE survey, and (c) a return envelope, were placed in each nursing staff member's mail box or handed out to them during a meeting. Completed surveys were placed in locked boxes located on their respective units or mailed to the local site coordinator.

\subsection{Factors of interest}

Outcome measures included the nurses' intention to leave their position within the next 12 months and absenteeism during the previous 3 months.

Explanatory variables were nurse characteristics including age, education and experience and also variables including job satisfaction, nurses' perceptions of staffing adequacy, overtime, number of patients cared for, and number of admissions and discharges on the previous shift.

\section{5 | Data analysis}

All data analyses were conducted using Stata version 14.2 (Statacorp, Texas). Descriptive statistics, including frequency and percentages of nurse characteristics and their working environment, were reported by country. Job satisfaction (including satisfaction with current position, satisfaction with occupation, and satisfaction with teamwork) was described by country as a dichotomous response, with mean and standard deviation.

To determine the association between absenteeism and intention to leave with factors of interest, logistic regression models were used and odds ratios reported. Multilevel logistic regression models were used to examine (a) the whole sample (fixed) effects of nurses' age, education, experience, full-time or part-time work, perceived adequacy of staffing, overtime, job satisfaction, and patient turnover, and (b) the random effects of the hospital and country in which the nurses worked, with the outcomes.

\section{4 | RESULTS}

\section{1 | Sample characteristics}

A total of 6,212 RNs in seven countries participated in the study. Across all countries, the RNs were predominantly female (91\%) and worked full time (85\%). More than a third (37\%) of nurses had more than 10 years experience in nursing and $20 \%$ had worked in their current unit for longer than than 10 years. Over $90 \%$ of nurses in Korea and Lebanon were younger than 35 years. The details of RN participant characteristics within each country are presented in Table 1.

Three-quarters (75\%) of all nurses perceived that staff levels were adequate at least $75 \%$ of the time, although lower rates were recorded for Italy and Lebanon (43\% and $48 \%$ respectively). Threequarters of Italian and Korean nurses cared for more than 10 patients on their previous shift compared to less than $20 \%$ of nurses from other countries sampled (Table 1).

The majority (90\%) of nurses in Korea reported they had experience of working overtime in the past three months compared to only $40 \%$ of nurses in Australia.

\subsection{Job satisfaction}

Satisfaction with current position, occupation and teamwork across countries are described in Table 2. Most nurses across all countries were satisfied with their job, with mean scores (range 1-5) satisfied with current position, occupation, and teamwork being 3.77, 4.04 and 3.87, respectively. The percentages of all nurses who answered "satisfied" and "very satisfied" with current position, occupation, and teamwork were $69 \%$, $78 \%$, and $72 \%$ respectively. Registered nurses working in Iceland (87\%), Australia (82\%) and the USA (78\%) reported the highest level of satisfaction with their current position whereas those in Turkey (36\%) and South Korea (31\%) reported the lowest. For satisfaction with occupation, RNs in Iceland again had the highest level (94\%), followed by the USA (89\%), with South Korea (38\%), and Turkey (30\%) again the lowest. Nurses from the USA (80\%) reported the highest level, followed by nurses in Australia (74\%) and Iceland (71\%). About half of the Italian (54\%) and Korean (48\%) nurses were satisfied with teamwork. 


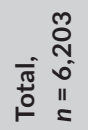

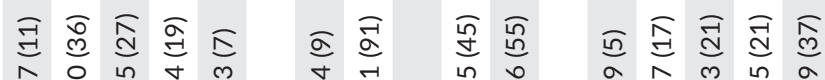

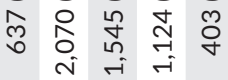

in

今ิ

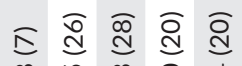

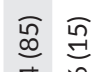

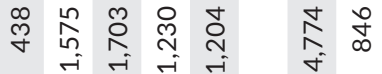

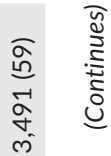

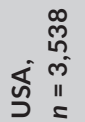

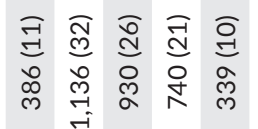

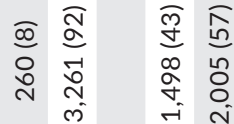

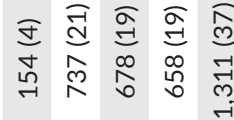

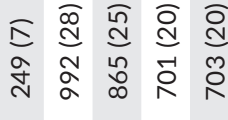

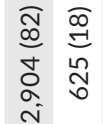

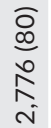

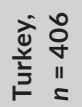

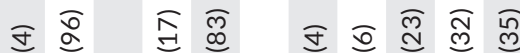

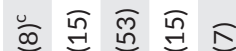

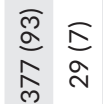

$\frac{\sqrt{5}}{\sqrt{2}}$

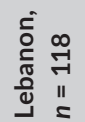

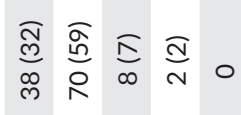

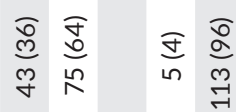

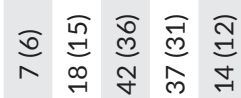

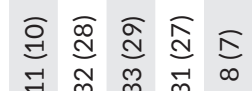

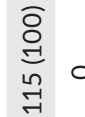

$\frac{a}{\infty}$

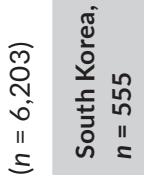

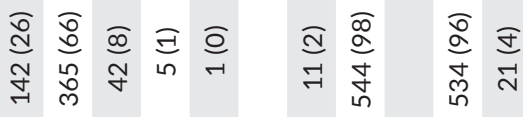

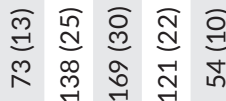

ब্ত

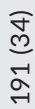

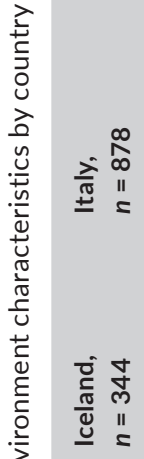

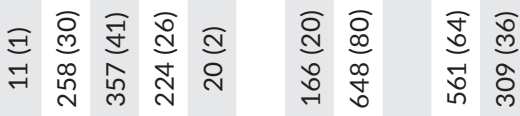

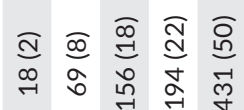

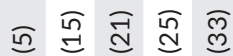

बे $\widehat{\sigma}$

$\underset{\substack{\mathrm{v} \\ \text { a }}}{\overline{1}}$

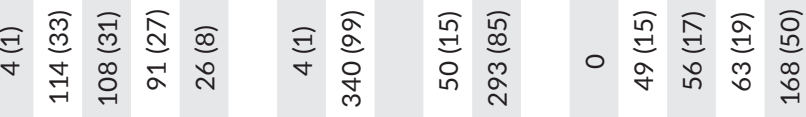

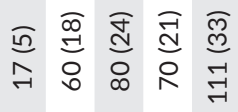

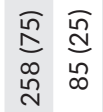

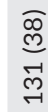

त

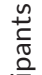

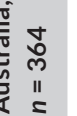

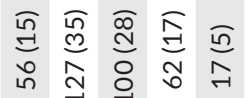

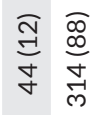

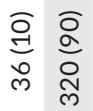

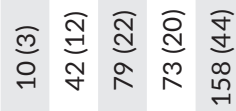

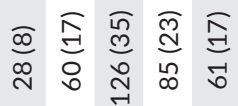

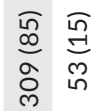

商

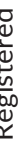

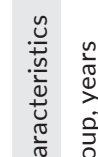

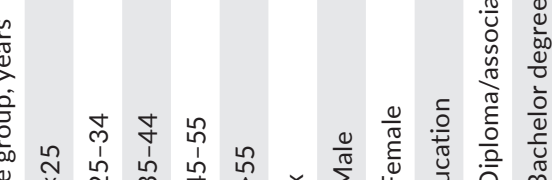

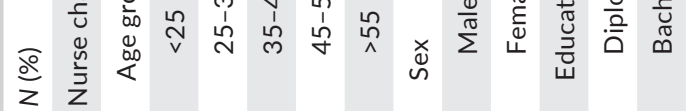

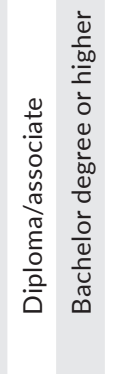

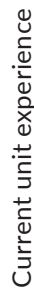

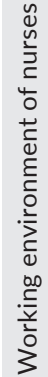

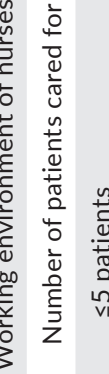




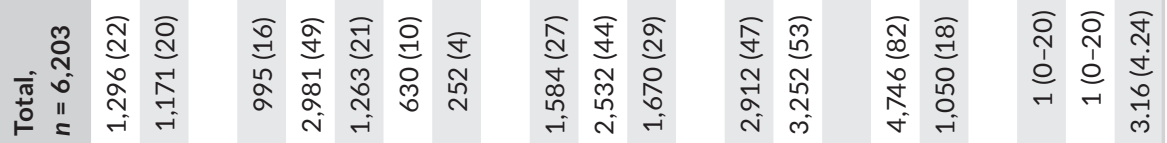

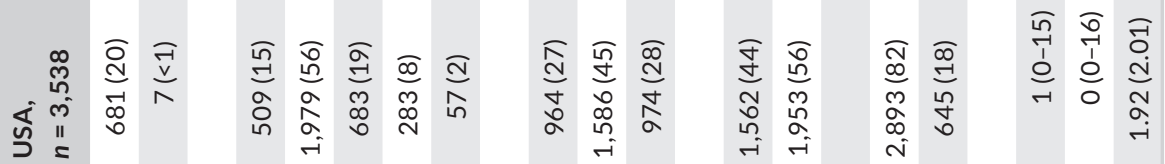

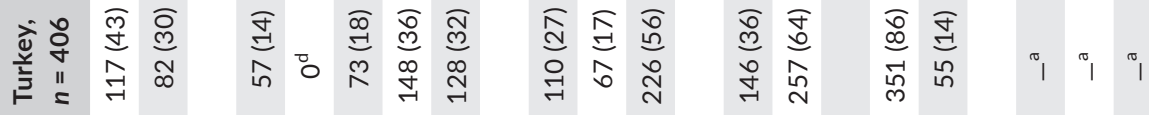

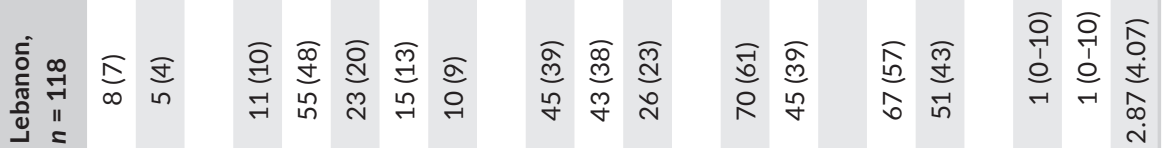

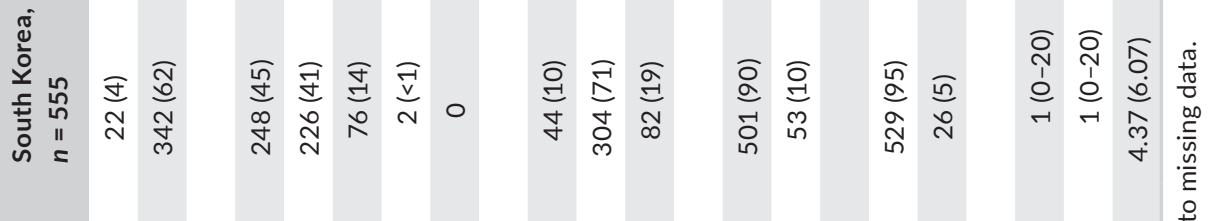

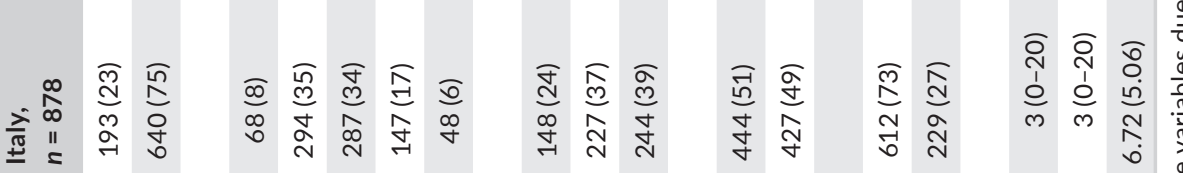

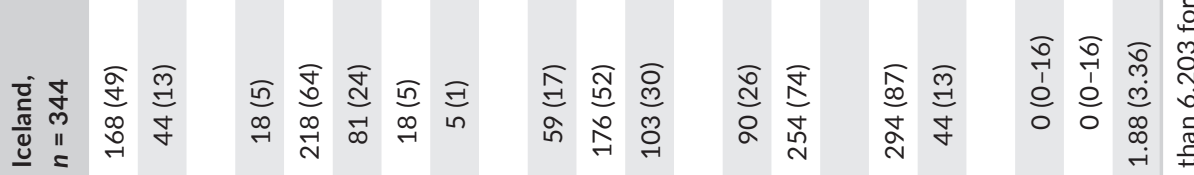

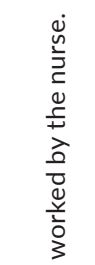


TABLE 2 Job satisfaction of nurses by country $(n=6,180)$

\begin{tabular}{|c|c|c|c|c|c|c|c|}
\hline & \multirow{2}{*}{$\begin{array}{l}\begin{array}{l}\text { Number of } \\
\text { responses }^{a}\end{array} \\
n\end{array}$} & \multicolumn{2}{|c|}{ Satisfied with current position } & \multicolumn{2}{|c|}{ Satisfied with occupation } & \multicolumn{2}{|c|}{ Satisfied with teamwork } \\
\hline & & $n(\%)^{b}$ & Mean $\pm S D^{d}$ & $n(\%)^{b}$ & Mean $\pm S D^{d}$ & $n(\%)^{b}$ & Mean $\pm S D^{d}$ \\
\hline Australia & 360 & 292 (82) & $3.97 \pm 0.89$ & c & c & $259(74)$ & $3.86 \pm 0.91$ \\
\hline Iceland & 342 & $297(87)$ & $4.11 \pm 0.71$ & $320(94)$ & $4.51 \pm 0.64$ & $240(71)$ & $3.81 \pm 0.84$ \\
\hline Italy & 881 & $574(66)$ & $3.66 \pm 0.90$ & $699(81)$ & $4.06 \pm 0.91$ & $462(54)$ & $3.46 \pm 0.96$ \\
\hline South Korea & 555 & $170(31)$ & $3.10 \pm 0.80$ & $209(38)$ & $3.14 \pm 0.90$ & $264(48)$ & $3.37 \pm 0.77$ \\
\hline Lebanon & 114 & $48(42)$ & $3.21 \pm 0.97$ & $58(51)$ & $3.35 \pm 1.17$ & $71(62)$ & $3.62 \pm 1.03$ \\
\hline Turkey & 405 & $146(36)$ & $3.05 \pm 1.07$ & $120(30)$ & $2.74 \pm 1.12$ & c & c \\
\hline USA & 3,523 & $2,741(78)$ & $3.94 \pm 0.83$ & 3,125 (89) & $4.30 \pm 0.76$ & $2,830(80)$ & $4.06 \pm 0.89$ \\
\hline Total & 6,180 & $4,268(69)$ & $3.77 \pm 0.92$ & $4,531(78)$ & $4.04 \pm 0.97$ & $4,126(72)$ & $3.87 \pm 0.93$ \\
\hline
\end{tabular}

Notes. SD, standard deviation.

${ }^{a}$ Maximum number of responses for all three satisfaction items of survey per country.

${ }^{b}$ Categorized into not satisfied (response 1-3) or satisfied (response 4 or 5).

${ }^{\mathrm{C}}$ Country did not collect this data.

${ }^{\mathrm{d}}$ Range of scores is 1 to 5 -higher scores indicate greater satisfaction.

\section{3 | Intention to leave}

Intention to leave position differed significantly across countries (Table 1). Registered nurses in Lebanon were the most likely to leave their position (odds ratio [OR]: 3.66 ; 95\% confidence interval [CI] 2.50-6.35) whereas RNs in South Korea had the lowest intention to leave (OR: $0.57 ; 95 \% \mathrm{Cl} 0.38-0.87$ ) compared to nurses in the USA (Table 3). After adjusting for nurse characteristics and work factors, nurses in Italy were approximately twice as likely to leave within 12 months compared to nurses from the USA (adjusted odds ratio [AOR]: 2.05; 95\% Cl 1.36-3.09). As nurses became older they were less likely to intend to leave (AOR $45-55$ versus < 25 years: $0.41 ; 95 \%$ $\mathrm{Cl}$ 0.28-0.62). Males were more likely to leave their current position but after adjusting for other factors the difference was not statistically significant.

More experienced nurses were less likely to leave (AOR $>10$ years vs. $<6$ months $0.71 ; 95 \% \mathrm{Cl} 0.55-0.92)$. However, nurses with higher education were more likely to leave their current position (AOR bachelor degree or higher vs. diploma: 1.46; 95\% Cl 1.19-1.80).

Whether the nurses worked full time or part time and the patient turnover on the nurses' last shift were not associated with the nurses' intention to leave after adjusting for other factors. An increased number of patients to care for increased the likelihood of the nurse to leave (AOR more than 10 patients vs. $1-5$ patients: 1.42 ; $95 \% \mathrm{Cl} 1.03-1.96$ ). Nurses perception of staffing adequacy greatly influenced their intention to leave with nurses who perceived the staffing to be adequate only $25 \%$ of the time compared to nurses who thought it adequate $100 \%$ of the time more likely to intend to leave (AOR: 1.72; 95\% Cl 1.17-2.54).

Satisfaction with their current position and with team work was associated with lower odds of intent to leave (AOR: $0.25 ; 95 \% \mathrm{Cl}$ 0.20-0.32; AOR: 0.72; 95\% Cl 0.59-0.90, respectively).

\section{4 | Absenteeism}

Iceland had the highest rate of absenteeism (74\%) and was closely followed by Australia (73\%). Conversely, South Korea had the lowest rate of absenteeism (10\%) (Table 1). Nurses from Iceland and Australia were much more likely to be absent from work than nurses from the USA (AOR: 2.35; 95\% Cl 1.45-3.82; AOR: 3.04; 95\% Cl 21.50-3.84, respectively) (Table 3). Older nurses were less likely to have been absent from work ( $A O R>55$ compared to < 25 years: 0.57 ; 95\% Cl 0.41-0.80).

Nurses that worked full time compared to part time (AOR: 1.56; 95\% Cl 1.30-1.88), those that worked between 1 and $12 \mathrm{hr}$ of overtime compared to none (AOR: $1.21 ; 95 \% \mathrm{Cl} 1.02-1.44$ ), and nurses who perceived the staffing on their unit to be less adequate ( $A O R$ perceived to be never adequate compared to adequate $100 \%$ of time: $2.10 ; 95 \% \mathrm{Cl} 1.32-3.32)$ were more likely to be absent from work.

Job satisfaction and patient turnover were not associated with absenteeism in the nurses sampled after adjusting for other factors.

\section{5 | DISCUSSION}

The findings of this study including seven countries across three continents show that RN characteristics, their job satisfaction, absenteeism, overtime, and intent to leave varies significantly between countries. After controlling for country and hospital clustering, the age, education, and experience of the nurse and perceived staffing adequacy of the nurses' unit are significantly associated with the rates of absenteeism and intent to leave. These findings confirm the significant contribution of staffing adequacy to nurse retention. 
TAB LE 3 Association between nurse participant demographics and their working environment with intention to leave and absenteeism for all countries sampled ${ }^{j}$

\begin{tabular}{|c|c|c|c|c|}
\hline & \multicolumn{2}{|c|}{ Intend to leave current position in next 12 months } & \multicolumn{2}{|c|}{ Absent from work in last 3 months ${ }^{k}$} \\
\hline \multicolumn{5}{|l|}{ Country } \\
\hline USA & 1.00 & 1.00 & 1.00 & 1.00 \\
\hline Turkey & $0.70(0.52-0.94)$ & $0.21(0.13-0.35)^{c}$ & $0.91(0.74-1.11)$ & $0.71(0.43-1.17)^{\mathrm{g}}$ \\
\hline Lebanon & $3.66(2.50-6.35)$ & $1.65(0.80-3.40)$ & $0.51(0.35-0.75)$ & $0.42(0.19-0.92)$ \\
\hline South Korea & $0.57(0.38-0.87)$ & $0.11(0.06-0.20)^{d}$ & $0.08(0.06-0.11)$ & $0.07(0.04-0.13)^{\mathrm{h}}$ \\
\hline Italy & $1.68(1.41-2.00)$ & $2.05(1.36-3.09)$ & $0.77(0.66-0.89)$ & $0.73(0.48-1.10)$ \\
\hline \multicolumn{5}{|l|}{ Age group, years } \\
\hline $45-55$ & $0.46(0.36-0.60)$ & $0.41(0.28-0.62)$ & $1.19(0.98-1.45)$ & $0.83(0.63-1.10)$ \\
\hline$>55$ & $0.41(0.28-0.59)$ & $0.44(0.26-0.73)$ & $0.82(0.64-1.06)$ & $0.57(0.41-0.80)$ \\
\hline \multicolumn{5}{|l|}{ Sex } \\
\hline Female & 1.00 & 1.00 & 1.00 & 1.00 \\
\hline Male & $1.71(1.38-2.11)$ & $1.11(0.83-1.48)$ & $0.92(0.77-1.09)$ & $0.80(0.64-1.01)$ \\
\hline \multicolumn{5}{|l|}{ Education } \\
\hline Diploma/Associate & 1.00 & 1.00 & 1.00 & 1.00 \\
\hline Bachelor degree or higher & $1.75(1.52-2.01)$ & $1.46(1.19-1.80)$ & $1.58(1.43-1.75)$ & $0.82(0.71-0.94)$ \\
\hline \multicolumn{5}{|l|}{ Current role experience } \\
\hline $0-2$ years & 1.00 & 1.00 & 1.00 & 1.00 \\
\hline$>2-5$ years & $0.87(0.74-1.03)$ & $0.86(0.68-1.09)$ & $1.08(0.95-1.23)$ & $0.98(0.82-1.18)$ \\
\hline$>5-10$ years & $0.74(0.61-0.89)$ & $0.68(0.52-0.88)$ & $1.10(0.95-1.27)$ & $0.95(0.78-1.15)$ \\
\hline$>10$ years & $0.40(0.32-0.50)$ & $0.39(0.28-0.55)$ & $0.79(0.68-0.91)$ & $0.73(0.59-0.90)$ \\
\hline \multicolumn{5}{|l|}{ Position hours } \\
\hline Part time & 1.00 & 1.00 & 1.00 & $1.00^{\mathrm{a}}$ \\
\hline Full time & $1.38(1.13-1.70)$ & $0.96(0.73-1.27)$ & $1.25(1.08-1.45)$ & $1.56(1.30-1.88)$ \\
\hline \multicolumn{5}{|l|}{ Number of patients cared for } \\
\hline 1-5 patients & 1.00 & $1.00^{f}$ & 1.00 & 1.00 \\
\hline 6-10 patients & $0.97(0.82-1.16)$ & $1.09(0.89-1.34)$ & $0.94(0.83-1.07)$ & $1.04(0.86-1.24)$ \\
\hline $11-20$ patients & $1.15(0.97-1.37)$ & $1.42(1.03-1.96)$ & $0.48(0.42-0.55)$ & $0.91(0.65-1.28)$ \\
\hline \multicolumn{5}{|c|}{ Perceived staffing adequacy, $\%$ of time } \\
\hline 100 & 1.00 & 1.00 & 1.00 & 1.00 \\
\hline 75 & $1.22(0.97-1.53)$ & $0.78(0.57-1.07)$ & $1.53(1.32-1.77)$ & $1.23(1.00-1.52)$ \\
\hline 50 & $2.15(1.68-2.74)$ & $1.01(0.71-1.43)$ & $1.76(1.49-2.09)$ & $1.40(1.10-1.79)$ \\
\hline 25 & $3.85(2.96-5.01)$ & $1.72(1.17-2.54)$ & $1.72(1.40-2.10)$ & $1.46(1.09-1.97)$ \\
\hline 0 & $2.94(2.08-4.14)$ & $1.98(1.14-3.42)$ & $1.83(1.39-2.43)$ & $2.10(1.32-3.32)$ \\
\hline
\end{tabular}


TABLE 3 (Continued)

\begin{tabular}{|c|c|c|c|c|}
\hline & \multicolumn{2}{|c|}{ Intend to leave current position in next 12 months } & \multicolumn{2}{|c|}{ Absent from work in last 3 months ${ }^{k}$} \\
\hline None & 1.00 & $1.00^{\mathrm{e}}$ & 1.00 & 1.00 \\
\hline $1-12 \mathrm{hr}$ & $0.83(0.70-0.99)$ & $0.96(0.80-1.15)$ & $0.95(0.84-1.08)$ & $1.21(1.02-1.44)$ \\
\hline None & 1.00 & 1.00 & 1.00 & 1.00 \\
\hline $\begin{array}{l}\text { Per patient admitted or } \\
\text { discharged }\end{array}$ & $1.03(1.01-1.05)$ & $1.00(0.97-1.03)$ & $0.97(0.96-0.99)$ & $0.99(0.9-1.01)$ \\
\hline \multicolumn{5}{|c|}{ Satisfied with current position } \\
\hline No & 1.00 & 1.00 & 1.00 & 1.00 \\
\hline Yes & $0.78(0.66-0.91)$ & $1.01(0.78-1.30)$ & $1.49(1.32-1.69)$ & $0.84(0.68-1.04)$ \\
\hline \multicolumn{5}{|c|}{ Satisfied with teamwork in current position } \\
\hline No & 1.00 & 1.00 & 1.00 & 1.00 \\
\hline Yes & $0.49(0.43-0.57)$ & $0.72(0.59-0.90)$ & $1.09(0.97-1.22)$ & $0.92(0.78-1.09)$ \\
\hline
\end{tabular}

Notes. OR: odds ratio; AOR: adjusted odds ratio; $95 \% \mathrm{Cl}$ : $95 \%$ confidence interval.

Adjusted for:

${ }^{a}$ country, hospital, age, education, unit experience, full or part-time, satisfaction with job, satisfaction with nursing, satisfaction with team, staffing perception, sex, patient turnover;

${ }^{\mathrm{b}}$ country, hospital, age, satisfaction with job, satisfaction with role, education, full or part-time, staffing perception, patient turnover;

${ }^{c}$ country, hospital, education, unit experience, full or part-time, satisfaction with job, satisfaction with nursing, staffing perception, sex;

${ }^{d}$ country, hospital, current experience, age, satisfaction with job, satisfaction with nursing, satisfaction with team, staffing perception, sex, patient turnover;

${ }^{\mathrm{e}}$ country, hospital, age, education, full or part-time;

f country and hospital;

${ }^{g}$ country, hospital, satisfaction with job, satisfaction with role, education, full or part-time, staffing perception;

${ }^{h}$ country, hospital, age, satisfaction with job, satisfaction with role, education, staffing perception, patient turnover;

icountry, hospital, age, satisfaction with job, education, full or part-time, staffing perception, patient turnover.

${ }^{\mathrm{j} A u s t r a l i a n}$ nurses did not complete intent to leave item.

${ }^{\mathrm{k}}$ Absent one shift or more.

In the past 3 months.

${ }^{m}$ Patient turnover is the total number of patients admitted or discharged under nurses care during previous shift.

${ }^{\mathrm{n}}$ Not estimated due to missing data.

The participants from Korea, Australia, and the USA reported the best perceived staffing adequacy, while those from Turkey, Italy, and Lebanon expressed the worst perceived staffing. For context, Italy had the highest patient load per nurse and least perceived staffing adequacy, whereas Korea had a similarly high patient load per nurse but also the highest perceived staffing adequacy. This contrast could be due to cultural differences in the role of the patients' families in the hospital setting. Previous research has suggested that, in countries like Korea, Lebanon, and Turkey, nurses are required to spend less time on the patient's activities of daily living, as this is often taken care of by the family of the patient (Kwak, Chung, Xu, \& Eun-Jung, 2010). This could contribute to higher perceived staffing adequacy, even with a higher patient load per nurse. In addition, there could be differences in number of assistive personnel across these countries that could help explain this difference. Perceived staffing adequacy has previously been associated with nurse satisfaction in general (Pineau Stam, Spence Laschinger, Regan, \& Wong, 2015). The patient turnover (admissions and discharges) was highest in Italy and lowest in Iceland and the USA.

Previous research suggests that staffing should be kept at a level that matches patient turnover to avoid negative patient and nurse outcomes (Hughes, Bobay, Jolly, \& Suby, 2015).

Absenteeism was found to be highest in Australia and Iceland and it was lowest in Korea and Lebanon. The majority of all participants across all countries except Korea and Lebanon reported having been absent from work during the previous three months. In a study in Norway, Roelen et al. (2013) found a negative association between satisfaction and absenteeism, with less satisfied nurses being more likely to report having been absent from work. Eighty-two per cent 
of their sample reported having been absent in the previous year, a comparable rate to that found in Iceland in this study. However, our results regarding job satisfaction and absenteeism in Iceland and Australia are somewhat paradoxical, these participants being the most satisfied and at the same time having the highest rate of absenteeism. Required work hours per week for full-time equivalent may vary between countries as well as number of shifts per week due to shift length, leaving out other variables influencing this relationship. Absenteeism may be due to a number of reasons embedded in workrelated, individual, and organizational factors (Baydoun, Dumit, \& Daouk-Öyry, 2016).

Overtime was highest in Korea, Iceland, and Italy, and lowest in Australia and Lebanon. The majority of all participants in all the countries except Australia reported having worked overtime in the previous three months. Research suggest that nurses who work overtime report lower quality of care, more care activities left undone, and poorer patient safety (Griffiths et al., 2014).

Intent to leave was highest in Lebanon where almost half of the participants expressed an intention to leave their job within a year. This is comparable to previous research in Lebanon, as El-Jardali et al. (2013) reported that only $35,1 \%$ of the nurses in their sample, indicated that they were likely or very likely to stay in their current position. In the current study, the participants from Korea, Iceland, and Turkey had the least intent to leave their job and the numbers from Iceland are similar to previous research on the Nordic countries, as Lindqvist et al. (2014) reported an average of $10 \%$ intent to leave across nurses in Norway, Sweden, and Finland. Similarly, Heinen et al. (2013) found a 9\% average rate of intent to leave across 10 European countries. Asking about intent to leave only gives an estimate of the potential turnover rates of nurses as individuals may frequently think about leaving their job without ever actually doing so. A recent study from Turkey indicated significantly higher rates of intent to leave (64\%) than in the current study, when nurses were asked how frequently they had thought about leaving their job (Yurumezoglu \& Kocaman, 2015). Intent to leave has consistently been found to be influenced by satisfaction, with more satisfied nurses being less likely to express an intent to leave their position or profession (Hairr et al., 2014; Sabanciogullari \& Dogan, 2015; Yurumezoglu \& Kocaman, 2015). Intent to leave has previously been associated with factors such as marital status (El-Jardali et al., 2013), work-family conflicts, satisfaction with pay, burnout, quality of teamwork (Estryn-Behar et al., 2007), job autonomy, peer support, physical and psychological demands, and longer hours at work (Han et al., 2015; Heinen et al., 2013).

The Icelandic participants were the most satisfied with their current job and occupation, which is in concordance with results from previous studies of Icelandic nurses where job satisfaction repeatedly measures high (Gunnarsdóttir, Clarke, Rafferty, \& Nutbeam, 2009; Kærnested \& Bragadóttir, 2012). Previous research on satisfaction has reported that $60 \%$ of nurses in the UK were satisfied with their work, and a relationship was found between satisfaction and nurse-patient ratios, indicating that a higher workload was associated with less satisfaction with work (Sheward, Hunt, Hagen,
Macleod, \& Ball, 2005). These numbers suggest that nurses in the Scandinavian countries are more satisfied with their current jobs than their peers in other countries. This could be partly due to the way the health care service is run in the Nordic countries, with a higher percentage of the workforce being employed in the public sector and frequent measuring of hospital performance. The high satisfaction scores for Australia and USA are similar. The Australian hospital was a public, accredited Magnet hospital. It could be hypothesized that the Nordic countries and Magnet hospitals have a less hierarchical hospital structure, where nurses have higher autonomy and influence in workplace decision-making (Eisler \& Potter, 2014), contributing to higher satisfaction in these countries.

In summary, this study found that nurse participants from Australia had high rates of absenteeism but most frequently perceived staffing to be adequate most of the time and had the lowest rate of overtime. Italy's nurse participants, on the other hand, were generally older had more experience, had the highest patient load, and the highest patient turnover. Participants from Korea and Turkey were least satisfied; however, they had the least intention to leave their job. Unlike Korea and Turkey, the Icelandic participants were highly satisfied. These results show the complex interplay of the measured variables, not to mention the many influences other non-measured variables may have on the relationship between absenteeism and intent to leave. Regardless of country and staff characteristics, staffing was identified as a significant predictor of absenteeism and intent to leave. Each additional 25\% higher rating of perceived staffing adequacy was associated with lower odds of absenteeism and intention to leave. These findings point to staffing adequacy as a pivotal variable in nurse retention.

\section{6 | LIMITATIONS}

There are a number of limitations to this study. Neither the hospitals nor the nursing staff members were selected randomly, so generalization of the findings to the country level cannot be made. The sampling of only one hospital in Lebanon and Australia is a further limitation and makes generalizing impossible. Although adjustment was made for the effects of the difference in countries and hospitals, we were unable to adjust estimates for differences between the units within the hospitals where the nurse participant worked. Nursing care delivery is affected by many factors, including culture, which could not be systematically measured.

Another potential limitation is that the respondents may not have understood the questions or might not have had the same idea about what was being asked. To mitigate this potential problem, focus groups of experts (senior nurses) in each country reviewed each question and ensured that the interpretation was the same in their country as in others. They also conducted test-retest procedures and achieved 0.70 or above before proceeding. Comparison is further complicated by variations in how different variables are measured-for example, by how intent to leave or absenteeism is defined, or how satisfaction or education is measured across studies. 
Previous research has also implicated burnout as an important variable in nurse satisfaction and intent to leave (Heinen et al., 2013; Kwak et al., 2010) and the lack of information on burnout, as well as many other variables not measured, in this study disallows for these relationships to be assessed.

\section{7 | IMPLICATIONS FOR NURSING}

All countries have problems with a shortage of nurses; it is therefore crucial to measure and understand factors associated with nurses' intention to leave and absenteeism. The message of this study is clear: regardless of country and hospital differences, nurse characteristics, staffing levels, and job satisfaction are significant contributors to absenteeism and intention to leave. However, there is a global present and foreseen nursing shortage. The findings of this study point to the importance of ensuring an adequate level of staffing. As Aiken et al. (2014, 2010 ) concluded, increased nurse staffing-however it is achieved-is associated with better outcomes for both nurses and patients, nurse managers and policy makers may need to address this challenge in a new and innovative way. Adding support workers may not be the answer (Griffiths et al., 2018), so it may be appropriate to look towards other solutions such as a modified interdisciplinary teamwork with increased input from advanced practice nurses with other professional health care disciplines such as physiotherapists, clinical pharmacists, ergonomists and clinical nutritionists working closer to the bedside around the clock. Providing nurses with the education and work environment that allow them to practise to their full potential is also a crucial factor for meeting the growing demand for professional nursing care (Institute of Medicine, 2010). With an aging population and a growing number of people surviving multiple complex diseases leading to chronic conditions, not to mention global warming consequences, the international society faces the paradox of a growing demand for nurses and at the same time a declining supply of practising nurses. Our findings indicate that young, less experienced nurses are at risk of leaving the profession and this implies a strong need to support and mentor nurses for some years after graduation. However, in respect to the best solutions, further research is required with a more rigorous study design to identify factors associated with absenteeism and nurses' intentions to leave after country, cultural, organizational, unit, and nurses' individual differences are taken into account.

\section{ETHICAL APPROVAL}

Ethical approval to conduct the survey was provided by the appropriate human research ethics committee for each site in each country.

\section{REFERENCES}

Aiken, L. H., Sloane, D. M., Bruyneel, L., Van den Heede, K., Griffiths, P., Busse, R., ... McHugh, M. D. (2014). Nurse staffing and education and hospital mortality in nine European countries: A retrospective observational study. Lancet, 383(9931), 1824-1830.

Aiken, L. H., Sloane, D. M., Cimiotti, J. P., Clarke, S. P., Flynn, L., Seago, J. A., ... Smith, H. L. (2010). Implications of the California nurse staffing mandate for other states. Health Services Research, 45(4), 904921. https://doi.org/10.1111/j.1475-6773.2010.01114.x

Aiken, L. H., Sloane, D. M., Clarke, S., Poghosyan, L., Cho, E., You, L., ... Aungsuroch, Y. (2011). Importance of work environments on hospital outcomes in nine countries. International Journal for Quality in Health Care, 23(4), 357-364. https://doi.org/10.1093/intqhc/ mzrO22

Baydoun, M., Dumit, M., \& Daouk-Öyry, L. (2016). What do nurse managers say about nurses' sickness absenteeism? A new perspective. Journal of Nursing Management, 24, 97-104. https://doi. org/10.1111/jonm.12277

Bragadóttir, H., Kalisch, B. J., Smáradóttir, S. B., \& Jónsdóttir, H. H. (2015). Translation and psychometric testing of the Icelandic version of the MISSCARE Survey. Scandinavian Journal of Caring Sciences, 29(3), 563-572.

Eisler, R., \& Potter, T. M. (2014). Transforming interprofessional partnerships. Indianapolis, IN: Sigma Theta Tau International.

El-Jardali, F., Alameddine, M., Jamal, D., Dimassi, H., Dumit, N. Y., McEwen, M. K., ... Murray, S. (2013). A national study on nurses' retention in healthcare facilities in underserved areas in Lebanon. Human Resources for Health, 11(49), https://doi. org/10.1186/1478-4491-11-49

Estryn-Behar, M., Van derHeijden, B. I., Oginska, H., Camerino, D., LeNezet, O., Conway, P. M., ... NEXT Study Group (2007). The impact of social work environment, teamwork characteristics, burnout, and personal factors upon intent to leave among European nurses. Medical Care, 45(10), 939-950. https://doi.org/10.1097/ MLR.0b013e31806728d8

Griffiths, P., \& Dall'Ora, C., Simon, M., Ball, ... RN4CAST Consortium (2014). Nurses' shift length and overtime working in 12 European countries: The association with perceived quality of care and patient safety. Medical Care, 52(11), 975-981. https://doi.org/10.1097/ MLR.0000000000000233

Griffiths, P., Recio-Saucedo, A., Dall'Ora, C., Briggs, J., Maruotti, A., Meredith, P....Missed Care Study Group (2018). The association between nurse staffing and omissions in nursing care: A systematic review. Journal of Advanced Nursing, https://doi.org/10.1111/ jan.13564.

Gunnarsdóttir, S., Clarke, S. P., Rafferty, A. M., \& Nutbeam, D. (2009). Front-line management, staffing and nurse-doctor relationships as predictors of nurse and patient outcomes. A survey of Icelandic hospital nurses. International Journal of Nursing Studies, 46(7), 920-927.

Hairr, D. C., Salisbury, H., Johannsson, M., \& Redfern-Vance, N. (2014). Nurse staffing and the relationship to job satisfaction and retention. Nursing Economics, 32(3), 142.

Han, K., Trinkoff, A. M., \& Gurses, A. P. (2015). Work-related factors, job satisfaction and intent to leave the current job among United States nurses. Journal of Clinical Nursing, 24(21-22), 3224-3232. https:// doi.org/10.1111/jocn.12987

Heinen, M. M., van Achterberg, T., Schwendimann, R., Zander, B., Matthews, A., Kózka, M., \& Schoonhoven, L. (2013). Nurses' intention to leave their profession: A cross sectional observational study in 10 European countries. International Journal of Nursing Studies, 50(2), 174-184. https://doi.org/10.1016/j. ijnurstu.2012.09.019

Hughes, R. G., Bobay, K. L., Jolly, N. A., \& Suby, C. (2015). Comparison of nurse staffing based on changes in unit-level workload associated with patient churn. Journal of Nursing Management, 23(3), 390-400. https://doi.org/10.1111/jonm.12147

Institute of Medicine (2010). The future of nursing: Leading change, advancing health. Washington, DC: The National Academies Press. 
International Council of Nurses (2007). Position statement. Geneva, Switzerland: International Council of Nurses.

International Council of Nurses (2013). The global shortage of registered nurses: An overview of issues and actions. Retrieved from https:// www.icn.ch/publications/the-global-shortage-of-registered-nurses-an-overview-of-issues-and-actions

International Council of Nurses (2014). Members. Retrieved from https:// www.icn.ch/members/members

International Council of Nurses (2018). Definition of nursing. Retrieved from https://www.icn.ch/who-we-are/icn-definition-of-nursing/

Kærnested, B., \& Bragadóttir, H. (2012). Delegation of registered nurses revisited: Attitudes towards delegation and preparedness to delegate effectively. Nordic Journal of Nursing Research, 32(1), 10-15. https://doi.org/10.1177/010740831203200103

Kalisch, B. J. (2015). Errors of omission: How missed nursing care imperils patients. Silver Spring, MD: American Nurses Association.

Kalisch, B. J., Lee, H., \& Rochman, M. (2010). Nursing staff teamwork and job satisfaction. Journal of Nursing Management, 18(8), 938-947. https://doi.org/10.1111/j.1365-2834.2010.01153.x

Kwak, C., Chung, B. Y., Xu, Y., \& Eun-Jung, C. (2010). Relationship of job satisfaction with perceived organizational support and quality of care among South Korean nurses: A questionnaire survey. International Journal of Nursing Studies, 47(10), 1292-1298. https:// doi.org/10.1016/j.ijnurstu.2010.02.014

Lindqvist, R., Alenius, L. S., Runesdotter, S., Ensio, A., Jylhä, V., Kinnunen, J., ... Tishelman, C. (2014). Organization of nursing care in three Nordic countries: Relationships between nurses' workload, level of involvement in direct patient care, job satisfaction, and intention to leave. BMC Nursing, 13(1), 1. https://doi. org/10.1186/1472-6955-13-27

Oulton, J. A. (2006). The global nursing shortage: An overview of issues and actions. Policy Politics and Nursing Practice, 7(3 Suppl.), 34S39S. https://doi.org/10.1177/1527154406293968

Pineau Stam, L. M., Spence Laschinger, H. K., Regan, S., \& Wong, C. A. (2015). The influence of personal and workplace resources on new graduate nurses' job satisfaction. Journal of Nursing Management, 23(2), 190-199. https://doi.org/10.1111/jonm.12113

Roelen, C. A. M., Magerøy, N., Van Rhenen, W., Groothoff, J. W., van der Klink, J. J. L., Pallesen, S., ... Moen, B. E. (2013). Low job satisfaction does not identify nurses at risk of future sickness absence: Results from a Norwegian cohort study. International Journal of Nursing Studies, 50(3), 366-373. https://doi.org/10.1016/j. ijnurstu.2012.09.012

Rosenkoetter, M. M., \& Nardi, D. A. (2007). American Academy of Nursing Expert Panel on Global Nursing and Health: White paper on Global Nursing and Health. Journal of Transcultural Nursing, 18(4), 305-315. https://doi.org/10.1177/1043659607305188

Sabanciogullari, S., \& Dogan, S. (2015). Relationship between job satisfaction, professional identity and intention to leave the profession among nurses in Turkey. Journal of Nursing Management, 23(8), 1076-1085. https://doi.org/10.1111/jonm.12256

Sheward, L., Hunt, J., Hagen, S., Macleod, M., \& Ball, J. (2005). The relationship between UK hospital nurse staffing and emotional exhaustion and job dissatisfaction. Journal of Nursing Management, 13(1), 51-60. https://doi.org/10.1111/j.1365-2834.2004.00460.x

Walker, J. (2010). The global nursing shortage: Migration, brain drain, and going forward. Retrieved from https://magazine.nursing.jhu. edu/2010/08/the-global-nursing-shortage/

Yurumezoglu, H. A., \& Kocaman, G. (2015). Predictors of nurses' intentions to leave the organisation and the profession in Turkey. Journal of Nursing Management, 24(2), 235-243.

How to cite this article: Burmeister EA, Kalisch BJ, Xie B, et al. Determinants of nurse absenteeism and intent to leave: $A n$ international study. J Nurs Manag. 2019;27:143-153. https:// doi.org/10.1111/jonm.12659 